\title{
An evaluation of polymer composites for car bumper beam
}

\section{Olumide Osokoya}

Department of Aeronautical and Automotive Engineering,

Loughborough University,

Loughborough, UK

Email: O.Osokoya-15@student.lboro.ac.uk

\begin{abstract}
Plastics were included in the array of automotive components materials in 1970s and today, they are the main materials for interior components of cars. Before then, traditional materials such as steel and iron were used for exteriors, interiors and structural parts. Modern technology reveals that plastics can be reinforced with certain materials to form new/novel materials called polymeric composites that can exhibit similar mechanical properties required for car structural components, such as metals. This is a major development and since legislations are getting stiffer concerning fuel consumption, the utilisation of lightweight components for cars are one of few logical measures of achieving standards. This article evaluates some polymer composites which are useful in replacing conventional materials for a car bumper beam, highlighting the fabrication methods of these composites and their properties to discuss the benefits of using them over conventional materials. The choice materials were compared using a material selection software, and the results show that carbon-fibre-epoxy composite has specific tensile strength which is about $360 \%$ greater than steel and $275 \%$ greater than aluminium. Also, glass-fibre-reinforced polypropylene composite and nylon-6-nanoclay nanocomposite, which have more competitive cost $/ \mathrm{kg}$ of material, have as much specific tensile strength as steel and aluminium.
\end{abstract}

Keywords: bumper beam; fabrication methods; lightweight; polymer composites; reinforcement; specific properties.

Reference to this paper should be made as follows: Osokoya, O. (2017) 'An evaluation of polymer composites for car bumper beam', Int. J. Automotive Composites, Vol. 3, No. 1, pp.44-60.

Biographical note: Olumide Osokoya is a recent graduate of Loughborough University having obtained a master's degree in Automotive Systems Engineering. His interest is in vehicle body engineering particularly in the research for innovative body designs and material composition to meet demands for efficient, safer and low-emission ground vehicles. He also has a degree in Mechanical Engineering from Obafemi Awolowo University, Nigeria and has published three more articles relating to energy efficiency in scientific journals. This article is a product of a coursework exercise carried out during his master's program at Loughborough University. 


\section{Introduction}

The choice of materials for vehicle components is one of the most important design parameters in automotive manufacturing. The type of material used has significant effects on the overall attractiveness of a vehicle which includes the aesthetics, cost, performance, emission levels and fuel economy. For vehicle manufacturers, weight is a very important factor in choosing materials for automotive components as it affects many other attributes, so active measures are recurrently taken to utilise lightweight materials for car components as much as possible (Heuss et al., 2012). Cost, however, is an important factor which is also taken into consideration in material selection. Conversely, most lightweight materials such as aluminium, magnesium, carbon fibres are more expensive than the heavier materials such as steel and cast iron for reasons including abundance and ease of fabrication (Szeteiová, 2010). In the decision-making process of the design; therefore, compromise is often met to balance both cost and weight requirements.

According to the US Department of Energy (2010), the composition of steel in car components was about $75 \%$ in 1977 which reduced to $65 \%$ in 2010 due to increase in polymers and composite used mostly for interior components. To achieve the goal of reducing fuel consumption of new vehicles by a factor of two by 2035 (Cheah et al., 2008), the US Department of Energy believes that the use of more lightweight materials such as aluminium, magnesium and polymer/composites will be required to push the composition of steel further down to $20 \%$ by 2035 (US Department of Energy, 2010). Although aluminium is considered as the most common car material for lightweight purposes, plastics are much lighter but are rarely used for structural components because of their lower mechanical properties compared to the metals (Szeteiová, 2010). However, with adequate reinforcement, the polymeric composites formed can have similar mechanical properties to steel and aluminium such as high strength and toughness while maintaining their light weight. Composites are formed by specific arrangement or overlaying of a stronger material, e.g. metal fibres or flakes with a weaker material to form a new one. Most polymer composites are formed using fibrous reinforcement arranged in a continuous or non-continuous manner within a polymer matrix (Gay, 2014). Common examples used are fibres of glass, carbon and aramid, to provide strength and stiffness for polymer matrices such as polyester, polyurethane, epoxy, polypropylene, polyethylene, nylon, etc. (American Chemistry Council, 2014). Polymer composites can also be formed by appropriately adding nanoparticles to a polymer matrix to form nanocomposites which are higher performance composites with excellent mechanical and electrical properties and lighter weight (Li et al., 2010).

Unlike ordinary plastics, polymer composites are useful for exterior and structural parts of a vehicle because of their reinforcements. They, therefore, have a major role to play in reducing vehicle weight and fuel consumption by replacing many steel components. This article evaluates the use of some polymer composites as alternatives for the regular materials used for car bumper beams. The property requirement for car bumper beams are first enumerated and the conventional materials used are discussed along with their manufacturing processes. Three polymer composites are chosen for evaluation which includes a review on the formation processes of the composites and discussions on the properties of the composites and how they match the requirement of the bumper. The benefits and cost effectiveness of replacing traditional materials for bumper beam with the selected polymer composites are also evaluated. 


\section{Description and properties of a car bumper}

Bumpers are essential parts of the crash management of a car. They are passive safety components that help to reduce aggressiveness of a crash. By placing them in the front end, they help to reduce physical damage and absorb shock at low impacts. In the earlier design of cars, bumpers were just rigid metal bars (Insurance Institue for Highway Safety. Safety, 2015). Later, thermoplastic elastomers were added as bumper covers (Drobny, 2014) and today, the typical design of a bumper structure shown in Figure 1 consists of a plastic cover over a reinforced bar of metal alloy especially steel and aluminium alloy.

Figure 1 Basic parts of the car bumper

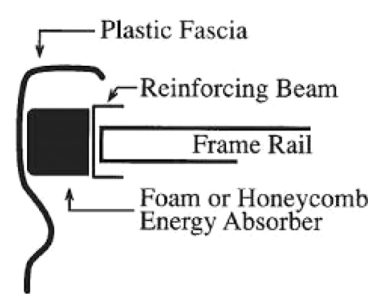

Source: (Jeyanthi, 2013)

Although the foam or honeycomb serves as the impact absorbing material and the plastic cover is useful for its aesthetics and protection purposes (Belingardi et al., 2015), the beam is the major structural part and thus the component of interest.

According to European Aluminium Association (2013), the car bumper has three major expectations, namely:

- to absorb energy at the start of a crash

- $\quad$ to minimise the damage of the vehicle at low and medium speed crashes

- to guide the crash forces into the body structure at high speed crashes to reduce passenger component intrusion.

As evident from the legislative expectation of a car bumper, the fundamental mechanical properties of the car bumper beam are strength and toughness. The strength of a beam is the magnitude of force it can withstand before deformation while toughness is its resistance to break or fracture under stress (Srinivasan, 2014). Another important property requirement is ductility, as the beam is expected withstand high level of deformation before fracture. The fracture of the car bumper after a collision could create a sharp end which itself constitutes a hazard.

Although not as important as basic requirements, it is also desired that bumpers are built to last. To ensure this, the material selected must be able to withstand corrosion. Also, as it pertains to other vehicle components, there should be possibility and ease of large scale manufacturing for the materials used. For a component like the bumper beam which can remain intact throughout the lifecycle of the car, the material recyclability is also important if not necessary considering new and upcoming legislations, for instance the Project ICARRE 95 in Europe that requires $95 \%$ by average weight of all end-of-life vehicles to be reused or recovered (Miller et al., 2014). Still on the topic of legislation, 
another important property which is also the motive of this research is that the car bumpers should also contribute to reduced weight and thus fuel efficiency of the vehicle.

\section{Common materials for car bumper}

\subsection{Steel bumpers}

Steel is the most common material used for automotive parts (Steel Market Development Institute, 2013). Steel beams have strength, stiffness and high energy absorption capacity making them very appropriate for car bumper. In addition to these key properties, they offer excellent resistance to corrosion, good fatigue properties and can be easily mass produced. These characteristics have made them well positioned in the bumper system market having 83\% market share in 2013 (Steel Market Development Institute, 2013). An example of a steel bumper beam is shown in Figure 2.

Figure 2 Steel bumper beam

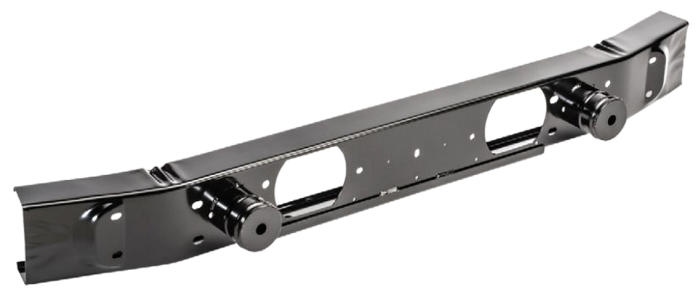

Source: (Steel Market Development Institute, 2013)

There are numerous steel grades available for manufacturers to choose from, ranging from mild steel to high strength steel and then ultra-high strength steel (UHSS). UHSS defined as steel with tensile strength above $700 \mathrm{MPa}$ (Sutar et al., 2015) is most commonly used for bumper beams (Steel Market Development Institute, 2013). Steel reinforcing beams are usually roll formed or hot stamped. Rolling is a method used in forming long cross-sections of steel from steel plates. The metal stock is passed through a set of rolls to reduce the thickness and create a uniform cross-section. After forming, these reinforcing beams are protected from corrosion by zinc coatings, aluminium coatings or electro-coatings (Steel Market Development Institute, 2013). Hot-stamped steels have higher tensile strengths. The process involves heating steel until it is red-hot and then pressing it into a die cavity to take the desired shape while it cools (Steel Market Development Institute, 2013). The pressing into the die is done by a sledge hammer while the hot steel is water-cooled.

\subsection{Aluminium bumpers}

Aluminium is the second material of choice for vehicle parts and also common for bumper beams. Many manufacturers find it useful as it offers weight savings of up to $50 \%$ when compared with steel while still maintaining safety and performance in a costeffective manner (Hirsch, 2011). In addition to the lower weight it offers, it meets the requirement of energy absorption and can also be mass produced (Hirsch, 2014). An example of aluminium bumper beam is shown in Figure 3. 
Figure 3 Aluminium bumper beam (see online version for colours)



Source: (Constellium, 2015)

Aluminium bumpers are mainly produced by extrusions which is forcing the aluminium through a die of the desired cross-sectional profile. Two known methods of forming aluminium extrusions into bumper beams are hydroforming and stretch bending. Stretchbending is the most accurate and quickest way and therefore is more suitable for mass production of bumper beams (Hirsch, 2011). It is a cold-forming process of bending initially straight aluminium extrusions over a curved die by applying axial tensions (European Aluminium Association, 2013). For hydroforming, the aluminium tube is placed inside a mould of the beam. It involves placing the extruded aluminium tube inside a mould of the beam and then at high pressure, hydraulic pumps are used to force the metal part until it expands to take the shape of the mould (European Aluminium Association, 2013).

\subsection{Plastic bumpers}

Plastic bumpers have been introduced in modern cars as they offer designers tremendous amount of freedom for styling. Plastics were once only used for fascia but currently, some vehicles use plastic reinforcing beams (American Chemistry Council, 2014). Some plastics commonly used today are polycarbonate/polybutylene, polyethylene and polypropylene GV et al., 2014. They have tensile strengths of up to $275 \mathrm{MPa}$ and flexural moduli up to 15,000 MPa (Steel Market Development Institute, 2013). An example of a plastic bumper beam is shown in Figure 4.

Figure 4 Plastic bumper beam (see online version for colours)

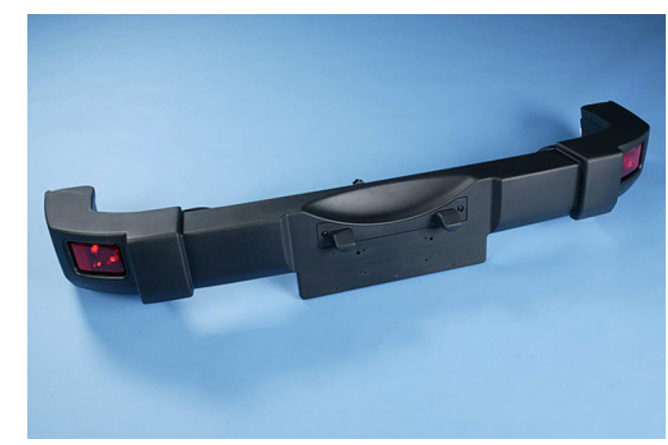

Source: (Constellium, 2015) 
The popular methods of fabricating plastic car bumper beams are injection moulding and compression moulding. By injection moulding, the polymeric powder is fed into a heated barrel and mixed, then forced into a mould cavity where it cools and hardens to the configuration of the cavity (James and Poucke, 2006). For compression moulding, the polymeric powder is preheated and then placed in an open, heated mould cavity. The mould is then compressed at high pressure to force the material into contact with all mould areas (James and Poucke, 2006).

\section{Polymer composites for bumper beams}

It is possible to use some polymer composites for bumper beams which are lighter than aluminium and also have the strength and stiffness required for crashworthiness. Plastics with about $30 \%$ reinforcement can yield composites with more than $100 \%$ increase in tensile strength and still offer lower weight and aesthetics (American Chemistry Council, 2014). There are various polymeric composites that have been formed and used in the material industry. Three of these composites are selected for evaluation of their usefulness as materials for car bumper beams.

\subsection{Carbon-fibre-epoxy composite}

Epoxy resin is a thermosetting polymer with high adhesive strength and high mechanical properties and therefore used for applications such as electronics, adhesives and structural composites (Wan et al., 2014). When reinforced with carbon fibre, they form composites which exhibit special advantages over monolithic materials, such as high strength, high stiffness, long fatigue life, low density, corrosion resistance, wear resistance, and environmental stability (Tserpes and Labeas, 2009).

Carbon fibre with epoxy offers a good balance for processing, part performance, and durability. Although there are many choices of materials for light weighting, carbonfibre-epoxy composites offer the greatest mass reduction for the equivalent stiffness or strength (American Chemistry Council, 2014). Automotive industry is now heavily focused on integrating carbon-fibre-epoxy composites into the vehicle structure. For instance, carbon-fibre-epoxy have been successfully used for door and window frame profile produced by Benteler-SGL for Porsche 911 GT3 Cup coupes cars shown in Figure 5 (Hexion, 2014).

Figure 5 Carbon-fibre/epoxy door and window frame (see online version for colours)

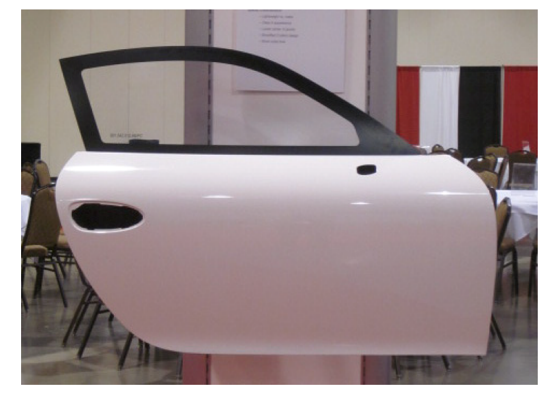

Source: (Hexion, 2014) 


\subsubsection{Manufacturing routes for carbon-fibre-epoxy beam}

\subsubsection{Resin transfer moulding}

Resin transfer moulding is a low-cost method capable of producing complex structures of different shapes (Potter, 2012). It is therefore an appropriate manufacturing route for producing a carbon fibre reinforced epoxy bumper beam. Resin transfer moulding works on the principle that injecting resin under pressure into a tool filled with fibrous reinforcement will cause a bulk flow of the resin to pass through the reinforcement and also each individual fibre will be wetted by the resin (Potter, 2012). For the fabrication of carbon-fibre-epoxy composite material, the epoxy is injected into a mould containing the carbon fibre reinforcement. The process starts by inserting the preformed carbon fibre into a two-part mould (male and female) and sealing it. The epoxy resin is mixed with a catalyst and then pumped into the mould through injection ports. The resin is best if it has a low viscosity as it can flow quickly through predesigned paths of the mould and permeate evenly. Then, the mould containing the epoxy resin is heated until the strength is attained, a process known as curing (Composite World, 2014). A diagrammatic representation of this fabrication method is shown in Figure 6.

Figure 6 Resin transfer moulding method (see online version for colours)

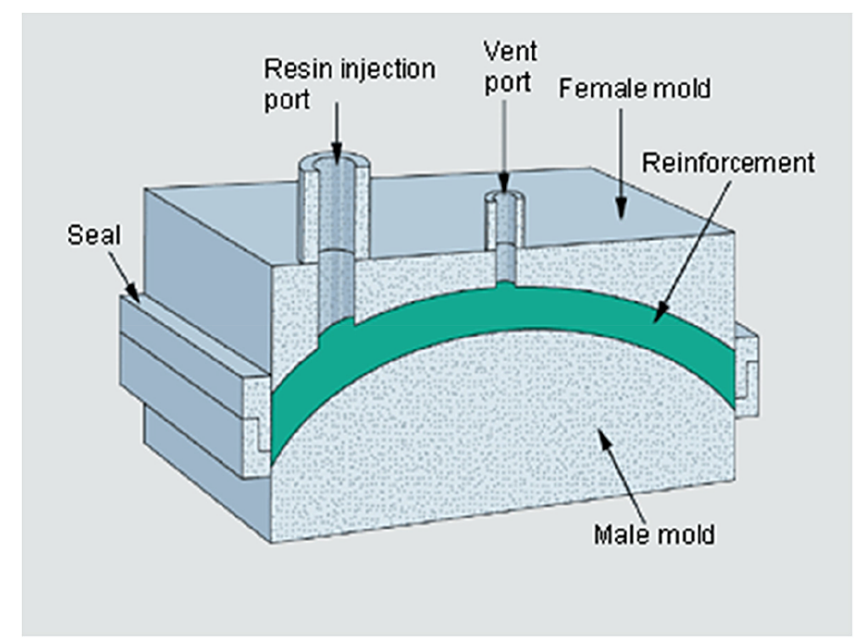

Source: (Wacker, 2016)

\subsubsection{Reaction injection moulding}

Reaction injection moulding method differs slightly from resin transfer in that there is no premixing of resin and catalyst but both are injected through separate streams (Composite World, 2014). The epoxy resin is fed into the mould containing the carbon fibre through a heated barrel for reduction in viscosity and then injected under pressure. The mould is then heated to a temperature lower than the glass transition temperature of the resin (Ishida and Zimmerman, 1994). The formed composite is then removed after curing. A schematic diagram of the reaction injection moulding process is shown in Figure 7. 
Figure 7 Reaction injection moulding process (see online version for colours)

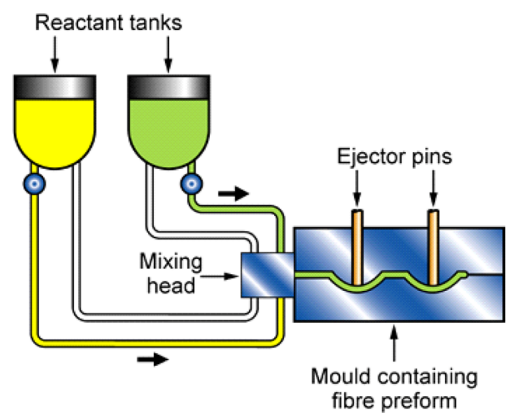

Source: (Granta Design Limited, 2015)

\subsection{Glass-fibre-reinforced-polypropylene composite}

Polypropylene is a commonly used plastic for automotive purposes but it has low impact and stiffness properties when compared with metals. Whereas, when reinforced with glass fibres, there are significant improvements in its strength and stiffness by a factor of two or more depending on the percentage of the glass fibres added while still maintaining its low weight (Granta Design Limited, 2015). Glass fibres is the commonly employed reinforcement for polypropylene because of its high availability and low costs (Suresh and Kumar, 2014). The glass fibres are the load-carrying members while the polypropylene transfer stresses between the fibres (Etcheverry and Barbosa, 2012).

\subsubsection{Manufacturing routes for glass-fibre-reinforced-polypropylene beam}

\subsubsection{Pultrusion}

Pultrusion is a common way of producing glass fibre reinforced plastics. In this method, the glass fibre is pulled from spools through a heated polymer bath and forced into shape as it passes bushings or forming guides. The mix is then passed through a heated die where it is shaped into the part to be formed and cured. Oftentimes, pultrusion produces good finishes which may not require post processing of the formed part except cutting into desired length (Composite World, 2014). A schematic of this is shown in Figure 8.

Figure 8 Pultrusion process of forming composites (see online version for colours)



Source: (Granta Design Limited, 2015) 


\subsubsection{Compression moulding}

Compression moulding employs a set of forged steel dies which compresses a sheet moulding compound. The sheet moulding compound is formed by sandwiching chopped glass fibres between the polymer and then rolling it to saturate the glass and eliminating trapped air. As shown in Figure 9, the sheet moulding compound is compressed by the steel dies which gives the shape of the polymer (Composite World, 2014). Compression moulding is a fast processing method for producing large number of parts so it is appropriate for mass production of car bumpers.

Figure 9 Compression moulding of a sheet moulding compound (see online version for colours)

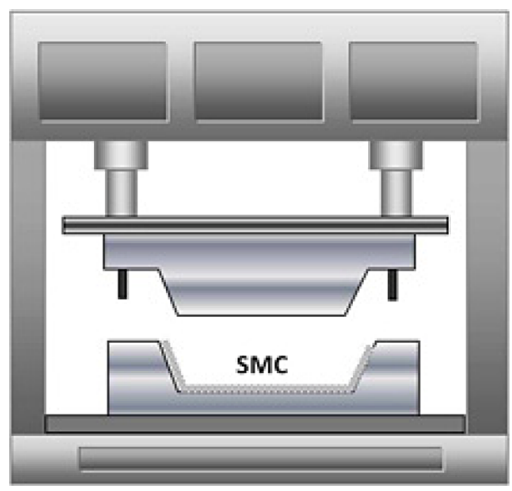

Source: (Molded Fibre Glass Companies, 2016)

\subsection{Nylon-6-nanoclay nanocomposite}

Polymer nanocomposites belong to a new class of composite materials formed by filling nanosized materials such as nanofibers, nanoclays, nanotubes, etc. within polymer matrices. The European Commission defines nanomaterial as a material containing particles for which $50 \%$ or more of the particles in the number size distribution has one or more external dimensions in the size range 1-100 nm (European Commission, 2011). The molecular level interactions between the nanoparticles and polymer matrices along with the presence of very high nanoparticle-polymer interfacial area play a major role in influencing the physical and mechanical properties of nanocomposites (Rahmat and Hubert, 2011). In addition to their exhibit excellent mechanical properties, they also display optical, electrical, thermal, magnetic and physicochemical properties (Nanowerk, 2012).

Nylon 6 (or polyamide 6) is a polymer possessing good toughness, high tensile strength, elasticity and lustre. It is used for a wide range of products requiring strength. This strength can match with the requirements for car bumpers when reinforced with nanoclay. Nanoclays are nanoparticles of layered mineral silicates. They are naturally occurring inorganic minerals. The most commonly used nanoclay for material reinforcement is montmorrillonite, a 2-to-1 layered smectite clay mineral with a platy structure (Nanocor, 2008). 


\subsubsection{Manufacturing routes for nylon-6-nanoclay nanocomposite beam}

\subsubsection{In situ polymerisation}

The commercialisation of polymer-layered silicate nanocomposites was initially limited by the lack of knowledge about their formation (Fornes and Paul, 2003). Since naturally occurring montmorillonite is hydrophilic and polymers are generally organophilic (tendency to form solvents with organic compounds), unmodified nanoclay disperses in polymers with great difficulty. The commercial processing of nylon-6-nanoclay nanocomposite was first developed by Toyota using an in situ polymerisation process which effectively exfoliates the aluminosilicate layers by an easily understood chemical mechanism. In the process, as illustrated in Figure 10, the sodium montmorillonite is mixed with an aminolauric acid in aqueous hydrochloric acid to protonate the aminolauric acid for an exchange with the sodium counter-ions. This is to ensure that the alkyl units of the resulting organo-clay contain terminal carboxyl groups. Under predetermined operating conditions, these carboxyl groups of the organo-clay will initiate ring-opening polymerisation of caprolactam to form nylon- 6 chains ionically bonded to the aluminosilicate platelets. The free energy of polymerisation stimulates the growth of these chains which continually pushes the platelets apart until exfoliation is completed (Fornes and Paul, 2003). By creating a nanocomposite via in situ polymerisation, improvement in desirable properties such as modulus, heat distortion under load, are significantly improved (Nanocor, 2008).

Figure 10 In situ polymerisation of nylon 6-nanoclay nancomposite (The Toyota Process)
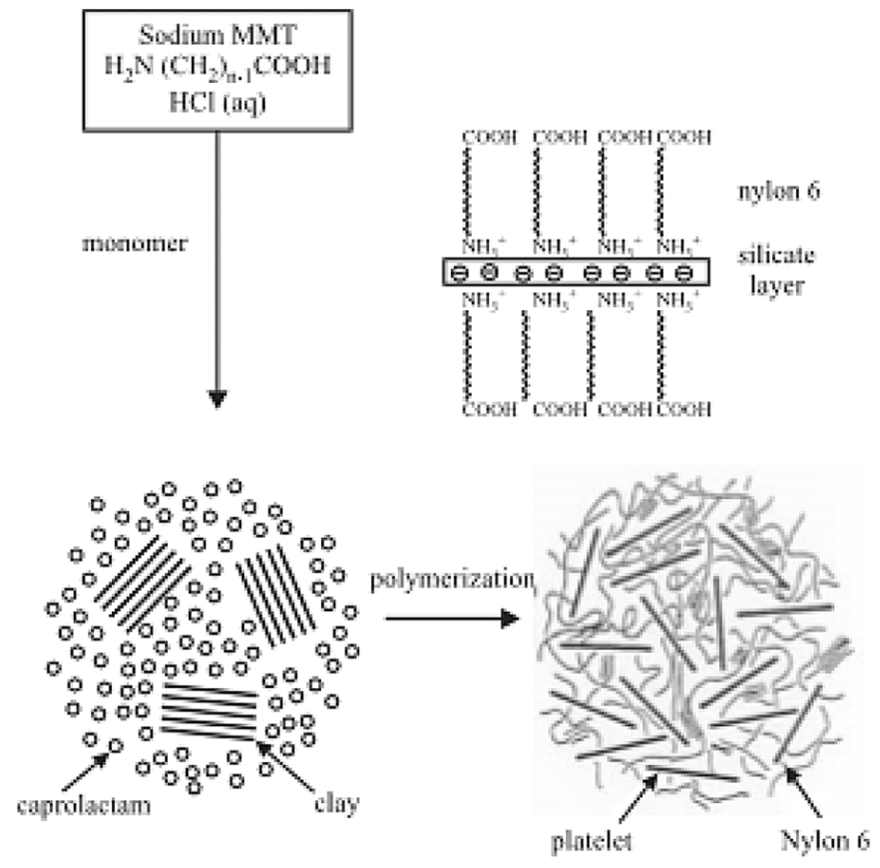

Source: (Fornes and Paul, 2003) 


\subsubsection{Melt processing}

Nanocomposites can also be obtained by direct polymer melt intercalation where polymer chains diffuse into the space between the clay layers or galleries (Cho and Paul, 2001). This approach can be combined with the usual polymer processing techniques (e.g. extrusion, injection moulding, etc.) to reduce the hybrid formation time. It is proposed that nanocomposites might be more widely used if they could be formed from existing polymers using conventional melt processing techniques as they are more economical and probably simpler than in situ polymerisation (Fornes and Paul, 2003; Cho and Paul, 2001). In the melt processing, the existing polymer is melted to form a viscous liquid and a high shear force is applied to disperse the nanoclay fillers in the mix. It is quite simple but the applied shear stress must be at optimum to achieve desired dispersion without causing a decline in the property of the nanocomposite (Choudhary and Gupta, 2011). Twin screw extrusion has proven to be most effective melt processing method for the exfoliation and dispersion of silicate layers. The combination of shear and good polymer-organoclay affinity makes it comparable to those produced by in situ techniques (Fornes and Paul, 2003).

\section{Benefits of using the polymer composites}

Legislation for new vehicle designs are constantly getting stiffer in terms of environmental friendliness, fuel efficiency, recyclability and safety of passengers and pedestrians. Change is therefore imminent in all areas of vehicle design in which material selection is core. Vehicle efficiency also increases through weight savings as about $40 \%$ of fuel consumption is attributed to inertia due to vehicle mass (Jeyanthi, 2013).

The main benefits of polymer composites come from the result of combining the properties of the base materials. Fibrous materials are known to be very strong and stiff and polymers are generally lightweight and flexible materials. Thus, the composites combine both advantages including better physical properties, recyclability and cheaper cost in some cases. These benefits are further enumerated in the following sections.

\subsection{Mechanical properties}

Polymer matrix composites are produced such that mechanical loads are supported by reinforcement while the polymer matrix bonds the fibres together to share the loads between them. The mechanical properties of conventional materials for car bumpers and that of the polymer composites are compared using data collected from an encyclopaedia for engineering materials (CES EduPack 2015 software) shown in Table 1. 
Table 1 Mechanical properties of conventional and proposed materials for car bumper beam

\begin{tabular}{|c|c|c|c|c|c|c|}
\hline & \multicolumn{3}{|c|}{ Conventional materials } & \multicolumn{3}{|c|}{ Polymer composite alternatives } \\
\hline & $\begin{array}{c}\text { High } \\
\text { strength } \\
\text { steel }\end{array}$ & $\begin{array}{c}\text { High } \\
\text { strength } \\
\text { al-alloy }\end{array}$ & $\begin{array}{c}\text { Polypropylen } \\
\text { e plastic }\end{array}$ & $\begin{array}{c}\text { Carbon } \\
\text { fibre-epoxy }\end{array}$ & $\begin{array}{c}\text { Glass fibre- } \\
\text { polypropylene }\end{array}$ & $\begin{array}{l}\text { Nylon-6- } \\
\text { nanoclay }\end{array}$ \\
\hline $\begin{array}{l}\text { Density } \\
\left(\mathrm{kg} / \mathrm{m}^{3}\right)\end{array}$ & $\begin{array}{c}7,800- \\
7,900\end{array}$ & $2,500-2,900$ & $890-910$ & $1,400-1,700$ & $1,320-1,340$ & 1,130 \\
\hline $\begin{array}{l}\text { Young's } \\
\text { modulus } \\
\text { (GPa) }\end{array}$ & $200-221$ & $68-80$ & $0.896-1.55$ & $69-150$ & $10.4-11.7$ & 5.00 \\
\hline $\begin{array}{l}\text { Yield } \\
\text { strength } \\
\text { (MPa) }\end{array}$ & $330-460$ & $95-610$ & $20.7-37.2$ & $221-276$ & $110-122$ & $83.4-84.1$ \\
\hline $\begin{array}{l}\text { Tensile } \\
\text { strength } \\
\text { (MPa) }\end{array}$ & $580-670$ & $180-620$ & $27.6-41.4$ & $350-500$ & $115-127$ & 75.2 \\
\hline $\begin{array}{l}\text { Elongation } \\
\text { (\% strain) }\end{array}$ & $19-22.8$ & $1-20$ & $100-600$ & $0.5-2$ & $1.53-1.85$ & 15 \\
\hline $\begin{array}{l}\text { Shear } \\
\text { modulus } \\
(\mathrm{GPa})\end{array}$ & $77.5-83.5$ & $25-28$ & $0.316-0.548$ & $27.8-60.5$ & $4.05-4.15$ & \\
\hline $\begin{array}{l}\text { Fracture } \\
\text { toughness } \\
(\mathrm{MPa} \sqrt{\mathrm{m}})\end{array}$ & $43.4-62.5$ & $21-35$ & $3-4.5$ & $25.8-38.3$ & $5.11-5.37$ & $4.03-4.5$ \\
\hline
\end{tabular}

Table 1 is a good reference but not sufficient to compare these materials due to some obvious disparities in material properties especially when considering Young's Modulus and Ultimate Tensile Strength. To cater for this, the graphs in Figures 11-13 compare the key properties for the car bumper beam in relation to the density of the material i.e. specific tensile strengths, specific yield strength and specific fracture toughness.

Figure 11 Comparison of specific tensile strength (see online version for colours)

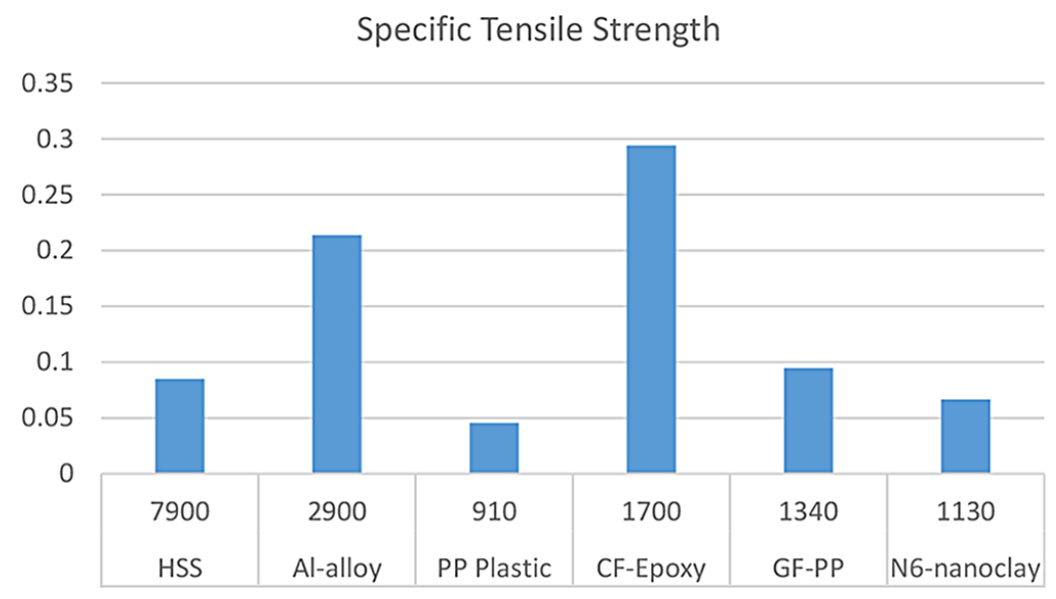


Figure 12 Comparison of specific yield strength (see online version for colours)



Figure 13 Comparison of specific fracture toughness

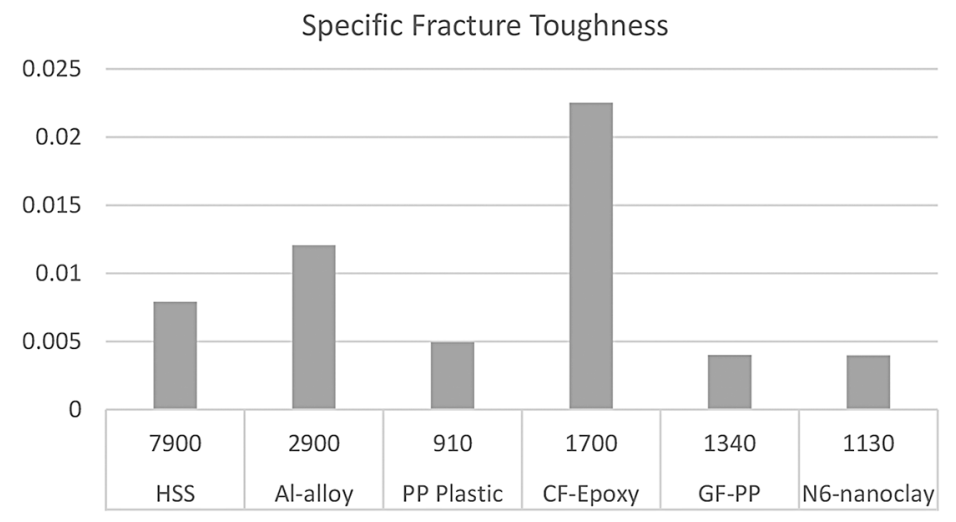

These graphs (Figures 11-13) show how the polymer composites closely match the key properties of the conventional materials necessary for car bumper beam. Carbon fibre reinforced epoxy composite especially, has higher values than steel and would provide about $70 \%$ weight reduction when it replaces a steel component. It is closely matched with Aluminium which only has a higher specific yield strength. Nevertheless, in comparison with aluminium, carbon fibre reinforced epoxy composite would still provide $40 \%$ more weight reduction.

Glass fibre reinforced propylene also has comparable specific strengths. Although lower than Aluminium, it has higher specific strengths when compared with steel. In addition, because of the very lightweight of polypropylene which is the base material, more weight reductions can be achieved with it. Its fracture toughness value is not very high because of its low ductility but to an extent, it will serve its purpose. Comparing it with unreinforced polypropylene, up to $100 \%$ in both specific tensile strength and yield strength is achievable.

The nylon-6-nanocomposite offers the best weight reduction of the three. It is seven times lighter than high strength steel and about three times lighter than aluminium. In addition to this, it has a higher specific yield strength than steel which makes it a possible alternative to replace many other steel components. 


\subsection{Physical properties}

In addition to their low densities, polymer composites also have other excellent physical properties. Polymer composites can be produced to have smooth surface finishes which is an important factor for aerodynamic drag. The car bumper is an exterior component of the vehicle and as such it has its own contribution to the total pressure drag the vehicle must overcome. Therefore, car bumpers made with polymer composites are beneficial in their contribution to weight reduction and drag reduction which cumulates to improved fuel consumption of a vehicle. In addition, polymer composites offer excellent resistance to corrosion and to chemical attack. This makes them suitable enough for parts that are expected to be long lasting requiring no replacements in the lifetime of the vehicle.

\subsection{Cost}

Total cost of producing composites is a concern and one of the main reasons for their non-utilisation. The numerous applications of metals and alloys led to more infrastructures for their production which accounts for their competitive costs. Table 2 shows the estimated cost of the current and suggest alternative materials for car bumpers as obtained from CES EduPack 2015 (Granta Design Limited, 2015).

Table 2 Cost comparison of alternative materials for car bumper

\begin{tabular}{lc}
\hline Material & Cost $(£ / \mathrm{kg})$ \\
\hline High strength steel & $0.494-0.544$ \\
Al-Alloy & $1.32-1.46$ \\
Unreinforced polypropylene & $1.32-1.51$ \\
Carbon-fibre-epoxy & $14.7-16.2$ \\
Glass-fibre-polypropylene & $2.03-2.68$ \\
Nylon-6-nanoclay & $4.12-5.49$ \\
\hline
\end{tabular}

The polymer composites are generally more expensive due to their uncommon fabrication methods. Glass fibre is the nearest alternative when considering cost. However, it is expected that as the materials become more commonly used, the prices will reduce.

\section{Conclusion}

Polymers are versatile materials with unique properties like low weight and flexibility. Their mechanical properties however are not adequate for many engineering applications. By reinforcing with fibrous materials, they are found to have comparable properties to the commonly used metals and alloys for automotive components and as such they hold great potential to be used for these components. In addition to weight reduction, some polymer composites offer other benefits such as drag reduction, good electrical and thermal properties which are also desirable for automotive applications. The evaluation shows that specific tensile strength and specific yield strength of the chosen composites are much higher than that of steel; with carbon-fibre-epoxy boasting of about $360 \%$ higher 
tensile strength and 300\% higher yield strength. It therefore holds great promise of replacing steel for bumper beams and many other structural components of a vehicle on the road to achieving more reduction in fuel consumption by light-weighting. Carbon fibre however is not as cheap as steel or aluminium which makes the glass-fibre polymer composite the next logical alternative for beams. Although the specific fracture toughness of the glass fibre polymer composite is not very competitive, its cost-competitiveness and higher specific strengths than steel makes it a worthy alternative. While the carbon-fibreepoxy composite can be regarded as a material for the future because of its current cost and there is still limited knowledge for mass producing the nylon-6-nanoclay nanocomposite, the glass-fibre-reinforced-polypropylene bumper beams are currently used in some sport cars.

\section{Acknowledgements}

The author wishes to thank the Loughborough University Department of Materials for the resources made available for the preparation of this work. The author also extends his appreciation to the coordinators of the master's program and the entire staff of Department of Aeronautical and Automotive Engineering for their contribution. The data presented, statements made, references provided and views expressed are solely the responsibility of the author.

\section{References}

American Chemistry Council (2014) 'Plastics and polymer composites technology roadmap for automotive markets', Washington, DC: American Chemistry Council - Plastic Division.

Belingardi, G., Beyene, A.T., Koricho, E.G. and Martorana, B. (2015) 'Alternative lightweight materials and component manufacturing technologies for vehicle frontal bumper beam', Composite Structures, Vol. 120, pp.483-495.

Cheah, L., Evans, C., Bandivadekar, A. and Heywood, J. (2008) 'Factor of two: Halving the fuel consumption of new US automobiles by 2035', in D. Sperling, J.S. Cannon (eds), Reducing Climate Impacts in the Transportation Sector, Netherlands: Springer Science, pp.49-71.

Cho, J.W. and Paul, D.R. (2001) 'Nylon 6 nanocomposites by melt compounding', Polymer, Vol. 42, No. 3, p.1083-1094.

Choudhary, V. and Gupta, A. (2011) 'Polymer/Carbon Nanotubes Nanocomposites', in S.Yellampalli (ed.), Carbon Nanotubes Polymer Nanocomposites, Rijeka, Croatia: InTech Publishers.

Composite World. (2014) Fabrication Methods. Available at: compositesworld.com/articles/ fabrication-methods (access 8 January 2016).

Constellium. (2015) Vehicle Crash Management Systems. Available at: http://www.constellium. com/aluminium-products/automotive-structures/automotive-system-solutions/vehicle-crashmanagement-systems (access 7 January 2016).

Drobny, J.G. (2014) Handbook of Thermoplastic Elastomers, Oxford, UK: Elsevier Science.

Etcheverry, M. and Barbosa, S.E. (2012) 'Glass fiber reinforced polypropylene mechanical properties enhancement by adhesion improvement', Materials, Vol. 5, No. 6, pp.1084-1113

European Aluminium Association. (2013) The aluminium automotive manual, Brussels: European Alumnium Association.

European Commission. (2011) 'Commission recommendation of 18 October 2011 on the definition of nanomaterial', Official Journal of the European Communities, 696. 
Fornes, T.D. and Paul, D.R. (2003) 'Formation and properties of nylon 6 nanocomposites', Polímeros, Vol. 13, No. 4, pp.212-217.

Gay, D. (2014) Composite Materials: Design and Applications, Florida: CRC Press.

Granta Design Limited. (2015) CES EduPack 2015, [Software] Cambridge, Granta Design.

GV, A.S., Reddy, P.S., Manoj, M. and Bhaskar, P. (2014) 'Impact analysis of a car bumper using carbon fiber reinforced PEI and S2 glass/epoxy materials by solid works software', International Journal of Science Engineering and Advance Technology, Vol. 2, No. 10, pp.565-569.

Heuss, R., Müller, N., Van Sintern, W., Starke, A. and Tschiesner, A. (2012) Lightweight, Heavy Impact, Munich: McKinsey \& Company.

Hexion. (2014) Hexion Carbon Fiber Epoxy Door Structure Wins "People's Choice" Award at ACCE. Available at: https://www.hexion.com/epoxyphenoliccomposites/automotive/news/ acce_award/ (access 8 January 2016).

Hirsch, J. (2011) 'Aluminium in innovative light-weight car design', Materials Transactions, Vol. 52, No. 5, pp.818-824.

Hirsch, J. (2014) 'Recent development in aluminium for automotive applications', Transactions of Nonferrous Metals Society of China, Vol. 24, No. 7, pp.1995-2002.

Insurance Institue for Highway Safety. Safety. (2015) Bumpers. Available at: http://www.iihs. org/iihs/topics/t/bumpers/qanda (Access 7 January 2016).

Ishida, H. and Zimmerman, D.A. (1994) 'The development of an epoxy resin system for the injection molding of long-fiber epoxy composties', Polymer composites, Vol. 15, No. 2, pp.93-100.

James, A. and Poucke, J.V. (2006) 'Long glass fiber polypropylene technology for automotive applications', in Society of Polymer Engineers' Automotive Composites Conference, Troy, Michigan, September 12-14, 2006, Michigan: Society of Plastic Engineers.

Jeyanthi, S.(2013) An Investigation of the Use of Natural Fiber Reinforced Thermoplastic Composites for the Automotive Bumper Beams, $\mathrm{PhD}$ thesis, Anna University, Chennai, India.

Li, S., Lin, M.M., Toprak, M.S., Kim, D.K. and Muhammed, M. (2010) 'Nanocomposites of polymer and inorganic nanoparticles for optical and magnetic applications', Nano Reviews \& Experiments, Vol. 1, No. 1, pp.1-19.

Miller, L., Soulliere, K., Sawyer-Beaulieu, S., Tseng, S. and Tam, E. (2014) 'Challenges and alternatives to plastics recycling in the automotive sector', Materials, Vol. 7, No. 8, pp.5883-5902.

Molded Fibre Glass Companies (2016) "Compression Molding Process/SMC," [Online]. Available at: http://www.moldedfiberglass.com/processes/processes/closed-moldingprocesses/compression-molding-process (access 7 January 2016).

Nanocor. (2008) Nanoclay Structures. Available at: http://www.nanocor.com/nano_struct.asp (access 7 January 2016).

Nanowerk. (2012) Polymer Nanocomposites Drive Opportunities in the Automotive Sector. Available at: http://www.nanowerk.com/spotlight/spotid=23934.php (access 8 January 2016).

Potter, K. (2012) Resin Transfer Moulding, Chapman \& Hall, London.

Rahmat, M. and Hubert, P. (2011) 'Carbon nanotube-polymer interactions in nanocomposites: a review', Composites Science and Technology, Vol. 72, No. 1, pp.72-84.

Srinivasan, M.R. (2014) Applied Solid State Physics: A Textbook on Material Science, Turnbridge Wells, UK: New Academic Science.

Steel Market Development Institute. (2013) Steel Bumper Systems for Passenger Cars and Light Truck, $5^{\text {th }}$ ed., Michigan: Steel Market Development Institute.

Suresh, S. and Kumar, V. (2014) 'Experimental determination of the mechanical behavior of glass fiber reinforced polypropylene composites’, Procedia Engineering, Vol. 97, pp.632-641. 
Sutar, V., Dharankar, C. and Raju, B. (2015) 'High strength steel for automotive applications', International Research Journal of Engineering and Technology, Vol. 3, No. 5, pp.966-968.

Szeteiová, K. (2010) 'Automotive materials: plastics in automotive markets today', International Conference Polymeric Materials in Automotive, pp 27-33, Slovak Republic: Slovak Academy of Sciences.

Tserpes, K.I. and Labeas, G.N. (2009) 'Mesomechanical analysis of non-crimp fabric composite structural parts', Composite Structures, Vol. 87, No. 4, pp.358-369.

US Department of Energy (2010) Materials Technologies: Goals, Strategies, and Top Accomplishments, DOE/GO-102010-3111, United States: US Department of Energy, 2010.

Wacker. (2016) Resin Transfer Moulding. Available at: http://www.wacker.com/cms/en/ industries/pl_composites/pl_comp_appl/resintransmould.jsp?country $=\mathrm{GB} \&$ language $=\mathrm{en}$ (access 8 January 2016).

Wan, Y., Gong, L. Tang, L., Wu, L. and Jiang, J. (2014) 'Mechanical properties of epoxy composites filled with silane-functionalized graphene oxide', Composites Part A: Applied Science and Manufacturing, Vol. 64, pp.79-89. 